\title{
Extent of Degenerative Changes in Ascending Aorta of Patients with Bicuspid Aortic Valve (BAV) - A Histopathological Study
}

\author{
Mukesh Kumawat, Shiv Kumar Choudhary*, Sachin Talwar, Velayoudam Devagourou, \\ Millind Hotte, Neeti Makhija, Ruma Ray \\ All India Institute of Medical Sciences, New Delhi, India \\ Email: *shivchoudhary@hotmail.com
}

Received October 7, 2012; revised November 9, 2012; accepted November 20, 2012

\begin{abstract}
Objective: To find out, whether the degenerative process of ascending aorta is limited to the aortic sinuses only or is extending to mid and distal ascending aorta of Bicuspid Aortic Valve patients. Method: A prospective consecutive study on 25 patients of BAV (undergoing aortic valve with \pm ascending aortic surgeries) was conducted from 1st Jan 2010 to 30th Dec 2011. Morphological and anatomical data of root and ascending aorta were recorded from echocardiography and computed tomography angiography. Intra-operatively, aortic tissue biopsy taken from three sites: sinus, mid, and distal ascending aorta. Histological evaluation of the aortic wall was based on criteria adapted from Schlatmann and Becker and from de Sa et al. The presence and degree of the 5 variables of degeneration were studied: Linear regression and correlation were used to get relationship between histopathological scoring (HPE-T) and aortic diameter for each site of ascending aorta. Results: Significant linear relation was found between aortic sinus diameter and HPE T score with $R$ value $=0.590$ ( $\mathrm{p}$ value 0.001$)$ and variance of $37.5 \%$. Analysis suggests that HPE T Score $=-5.139+(0.188 \times$ Ao. Sinus Diameter in $\mathrm{mm}$ ). No significant linear relation could be established between mid and distal ascending aorta diameter and HPE T scoring. Conclusion: In BAV patients, a definite relationship between degenerative changes of aortic media and aortic diameter was found and was limited up to the sinus level only. Thus, the study reinforces the thought of replacing aortic sinus too while dealing with aortic valve, even without significant dilatation. By this aggressive management of aortic root, progression of aortic dilatation or dissection can be prevented in bicuspid aortic valve patients.
\end{abstract}

Keywords: Bicuspid Aortic Valve; Ascending Aorta; Degenerative Changes

\section{Introduction}

The Bicuspid Aortic Valve (BAV) is the most common congenital cardiac malformation, occurring in $1 \%-2 \%$ of the population [1]. The presence of a BAV is an independent risk factor for progressive aortic dilation, aneurysm formation, and dissection. It is believed that the vascular complications of BAV disease are not secondary to valvular dysfunction and can manifest in young adults without significant aortic stenosis or regurgitation and in patients whom the native BAV was replaced by prosthesis $[2,3]$. In fact, $50 \%$ of young patients with normally functioning BAVs have echocardiographic evidence of aortic dilation [2].

A good proportion of the patients of BAV possessing stenotic or regurgitant lesion requiring surgery have developed enough aortic degenerative changes to be addressed as impending aneurysm. Such aortic changes very

"Corresponding author. soon lead to aneurysm/dissection formation. With the advent of valve repairing aortic root replacement, the investigators have recommended aortic root replacement, if the proximal aortic diameter exceeds $5.0 \mathrm{~cm}$ in isolation ( $4.5 \mathrm{~cm}$ if aortic valve is diseased) in patients with BAV even without significant valvular dysfunction [4].

However, there is very few literature to suggest the extent of degenerative changes. It is not clear as to what extent degenerative changes involve the aorta. Are the changes limited to the aortic sinuses and proximal ascending aorta or even the distal ascending aorta is also involved? In clinical practice, as resection only involves the sinuses and proximal aorta, if fulfills the criterion of aortic dilatation and no root replacement if aortic diameter $<4.5 \mathrm{~cm}$. This way, we might be leaving a degenerated segment in situ which may predispose the patient to future dissections and aneurysm formation. Therefore some further studies are needed to acknowledge the extent of degenerative process in ascending aorta of BAV 
patients. Thus, the purpose of this pilot study was to find out the extent of aortic involvement in the degenerative process in patients with BAV so that, consensus can be made over the length of excision of dilated aorta and management of non-dilated $(<4.5 \mathrm{~cm}$ diameter) ascending aorta.

\section{Objective}

To study the extent of aortic involvement in the degenerative process in ascending aorta of BAV patients presenting with aortic vulvular lesion.

\section{Material and Method}

The present study, conducted at C.N Center of All India Institute of Medical Science. This prospective study of 25 patients of BAV (Bicuspid Aortic Valve) was conducted from 1st Jan 2010 to 30th Dec 2011, on the patients who underwent aortic valve surgery or ascending aortic surgery and gave informed consent. Ethical clearance was taken from ethical committee of AIIMS.

After taking informed consent patients were evaluated clinically. All echocardiographic data, Computed Tomographic Angiography (CT-Angio) data collected. Details of aortic valve lesion, measurements of aortic annulus, aortic root, mid of ascending aorta and distal ascending aorta diameters were noted.

\subsection{Sampling}

Patients operated by standard techniques of aortic valve replacement. At time of aortic cannulation, aortic biopsy was taken from distal ascending aorta. Similarly during insertion of cardioplegic cannula, aortic wall biopsy was taken by using side-biting clamp. While excising the aortic valve, biopsy was taken from non-coronary sinus of aorta. Biopsy samples were of full thickness, approximately 4 $\mathrm{mm}$ diameter round pieces of aortic wall. Samples were named as 1, 2 and 3 corresponding to sites: Site $1=$ aortic sinus (NCC), Site $2=$ mid of ascending aorta (cardioplegic cannulation site) and Site 3 = distal ascending aorta (aortic cannulation site). Every individual has different length of ascending aorta but approximately the site of aortic cannulation matches with the site (i.e. just below the origin of innominate artery) where the diameter of distal ascending aorta is measured by CT scan. The cardioplegia cannulation site also approximately corresponds to the mid of ascending aorta as imaged in CT scan. The biopsy for sinuses, were taken after aortotomy, from noncoronary sinus, which almost dictates the maximum aortic sinus diameter site in CT scan. To understand the site of specimens, check Figure 1.

\subsection{Sample Processing}

Collected samples were kept in $10 \%$ Formalin, labeled in codes (patient and site coding in numbers) and carried to pathology lab. Biopsy tissues were processed overnight to remove formalin, wax embedding done and blocks prepared. Sectioning of blocks was done at $\approx 5$ microns. Slides were prepared and stained.

Stains used were H \& E (Hematoxylin and Eosin), MT (Masson Trichrome stain), VVG (Verhoeff's Van Gieson's Stain) and AB-PAS (Alcian Blue and Periodic Acid Shiff's).

\subsection{Data Generation}

The histological evaluation of the media of the aortic wall was based on criteria adapted from Schlatmann and Becker [5] and from de Sa et al. [6] The presence and degree of the 5 variables were studied: 1) fibrosis, 2) medionecrosis, 3) cystic medial necrosis (mucoid material accumulation), 4) changes in smooth muscle cells orientation, and 5) elastic fragmentation. Each variable was graded from 0 to 3 according to the severity of the

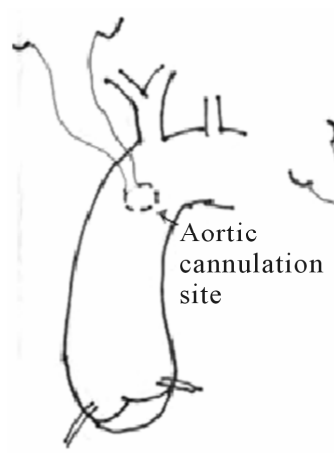

(a)

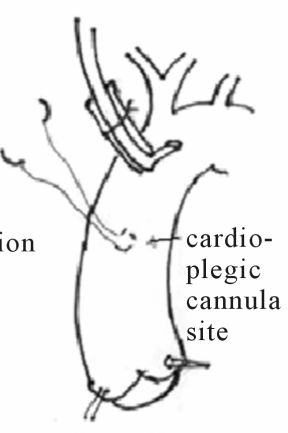

(b)

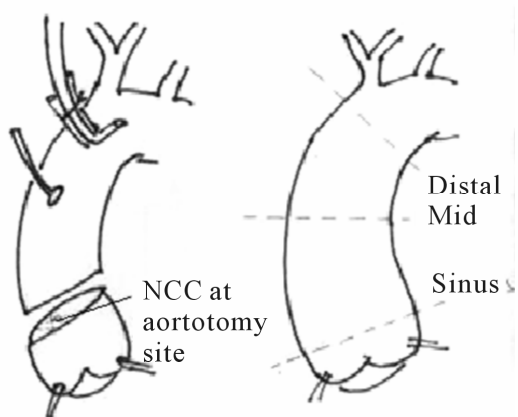

(d)

Figure 1. Schematic presentation of ascending aorta showing three site of aortic biopsy sites used in the study and comparing it with three aortic diameter measurement site in CT Images. (a) Site 3-aortic cannulation site; (b) Site 2-cardioplegic cannulation site; (c) Site 1-noncoronary sinus at aortotomy site; (d) schematic CT image showing standard measurements sites of ascending aorta. 
process when examined at a magnification of 100 or 200 times by light microscope (Olympus). Aortic samples from all three sites were graded along five parameters which gave a total degenerative score for that aorta (Figures 1-5 shows degenerative changes in the media of aortic wall). For histopathological grading system check Annexure 1.

\subsection{Data Analysis}

Data Analysis was done by using SPSS 14.0. All data were recorded as absolute numbers. Non parametric tests and descriptive statistics were used to calculate mean, standard deviation of variables like age, height, aortic diameters and correlating them with other parameters. Linear regression and Pearson Correlation used to get relationship between HPE Score, aortic diameters and other parameters, at each aortic site.

\section{Results}

Total numbers of patients studied were $25(100 \%)$. Age of the patients ranged from 15 years to 78 years and $76 \%$

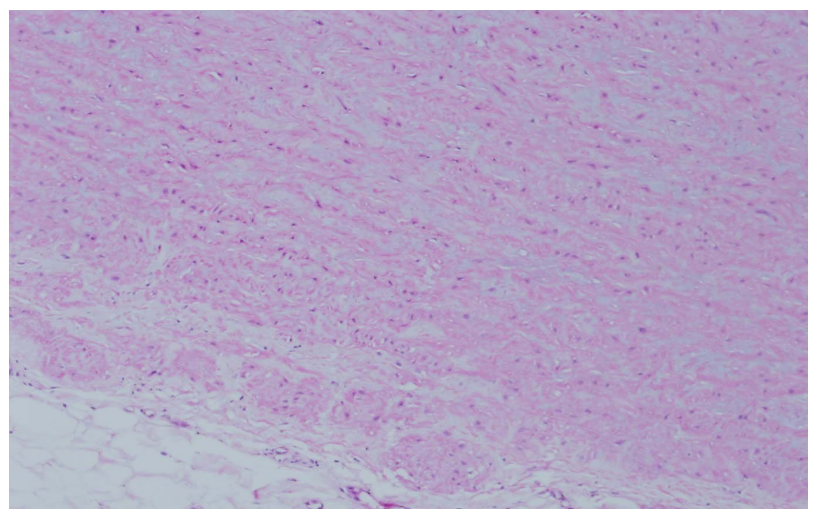

Figure 2. H\&E stain-showing smooth muscle cell disarray with myxoid changes in media of ascending aorta with BAV.

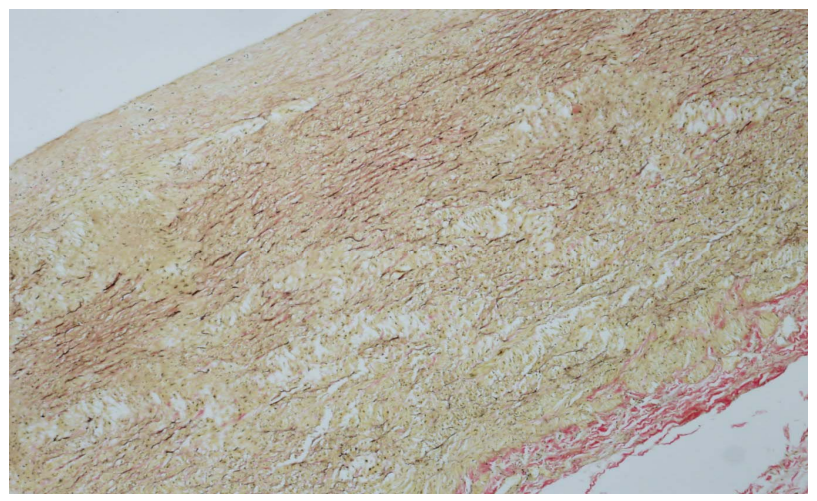

Figure 3. MT stain - showing elastic fragmentation with loss of elastic tissue in media of ascending aorta of patient with BAV.

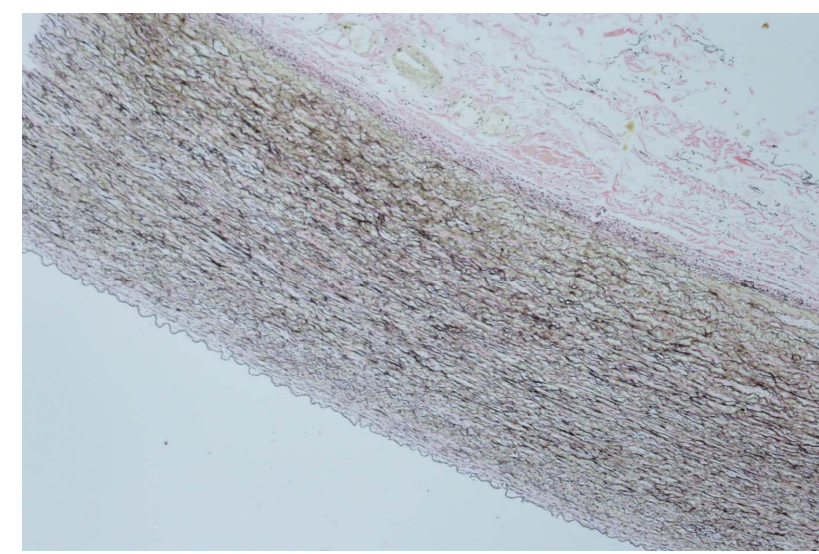

(a)

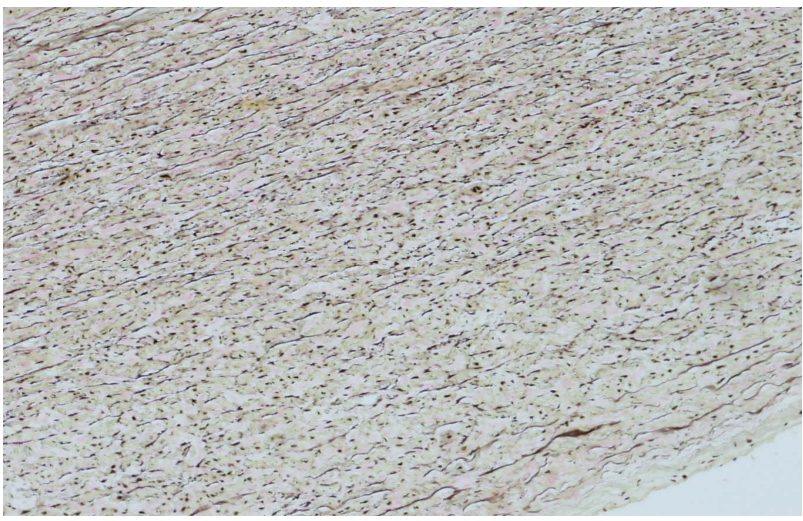

(b)

Figure 4. VVG stain. (a) Low power; (b) High powershowing elastic fragmentation in media of ascending aorta with BAV.

$(\mathrm{n}=19)$ of patients were in age group of $21-50$ years. The mean age, height and Body Surface Area (BSA) were $37.36 \pm 13.54$ years, $167.4 \pm 5.65 \mathrm{~cm}$ and $1.69 \pm 0.16 \mathrm{~m}^{2}$ respectively. Demographic profile of this study showed a male preponderance $(n=23,92 \%)$.

The mean aortic diameter at sinus, mid of ascending and distal ascending aorta were $40.12 \pm 7.54 \mathrm{~mm}, 40.04$ $\pm 8.95 \mathrm{~mm}$ and $34.16 \pm 6.22 \mathrm{~mm}$ respectively. Patients of bicuspid aortic valve presented with aortic stenosis in 7 $(28 \%)$, aortic regurgitation in $7(28 \%)$ and aortic stenosis with regurgitation in $11(44 \%)$. Aortic valve replacement was done in $20(80 \%)$ and Modified Bentall's procedure was required in $5(20 \%)$ patients. Out of 20 patients requiring AVR, two patients also underwent aortoplasty.

Patients were categorized according to their aortic diameters (Dimensions taken from CT scan) in 5 subgroups as: Diameter $\leq 35 \mathrm{~mm} ; 36$ - $40 \mathrm{~mm} ; 41-45 \mathrm{~mm} ; 46$ - 50 $\mathrm{mm} ; \geq 51 \mathrm{~mm}$. The mean of total HPE-Score of individual degenerative characters was calculated for all patients in a subgroup. A composite mean score was calculated by adding all the mean HPE-Score of various degenerative changes in a subgroup. 


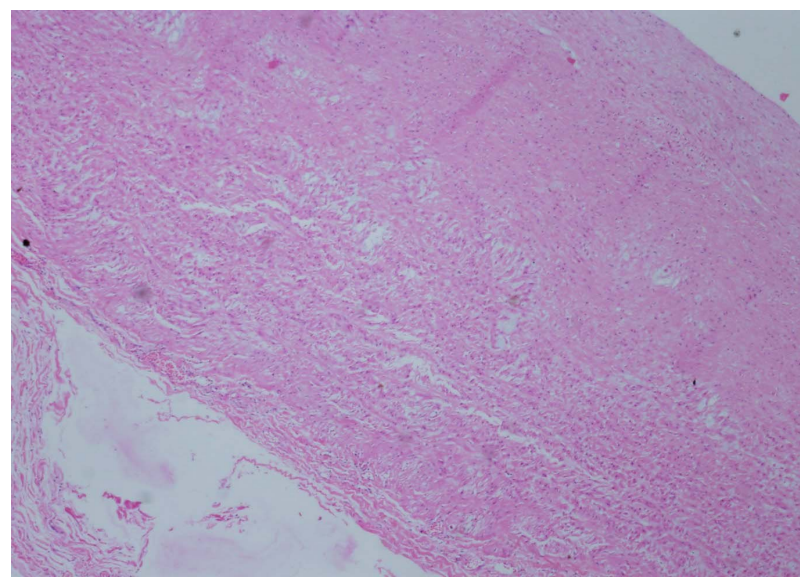

(a)

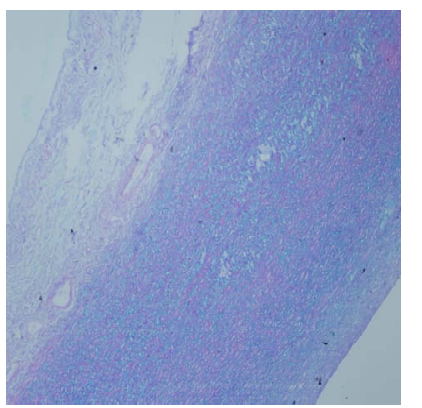

(b)

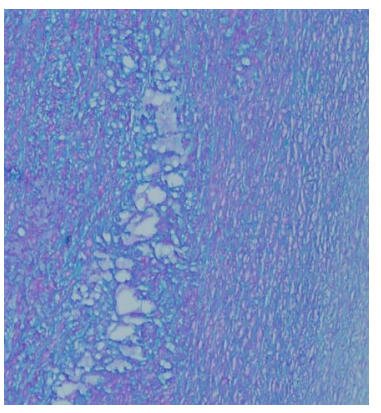

(c)
Figure 5. (a) H\&E stain; (b), (c) AB PAS stain; (c) High power image. Showing cystic medial degeneration in media of ascending aorta patient with BAV.

\subsection{Findings at Aortic Sinus Level (Table 1)}

For diameter of aortic sinus $\leq 35 \mathrm{~mm}, 36-40 \mathrm{~mm}, 41$ $45 \mathrm{~mm}, 46-50 \mathrm{~mm}$ and $\geq 51 \mathrm{~mm}$ the mean HPE T Score was $1.5,3.3,3.8,4.33$ and 8 respectively. Mean composite HPE Score increases with the increase in aortic sinus diameter. Observation reflects that, for every unit increase in diameter of aortic sinus there is some degree of increases in mean composite score. Pearson Correlation was calculated taking dependent variable as HPE T-Score at site 1 (aortic sinus) and independent variable as aortic diameter at sinus level. Significant linear relation was found between aortic sinus diameter and HPE T score at site 1 with $R$ value $=0.590$ ( $\mathrm{p}$ value 0.001$)$ and variance of $37.5 \%$. Analysis suggests that HPE T Score $=-5.139$ $+(0.188 \times$ Ao Sinus Diameter in $\mathrm{mm})$.

\subsection{Findings at Mid Ascending Aorta Level (Table 2)}

For aortic diameters: $\leq 35 \mathrm{~mm}, 36-40 \mathrm{~mm}, 41-45 \mathrm{~mm}$, $46-50 \mathrm{~mm}$ and $\geq 51 \mathrm{~mm}$ the mean composite HPE T score was $1.3,1.25,2.25,2.66$ and 1.75 respectively. Above mentioned data reveals little relation between increases in aortic diameter at mid ascending aorta and mean HPE $\mathrm{T}$ score, thus requiring co-relation studies? No significant linear relation could be established between mid ascending aorta diameter and HPE T scoring for site 2 as $R$ value was 0.124 (p value 0.278 ) with variance of $6.1 \%$.

Table 1. Histopatholocical grading at site 1-Aortic sinus.

\begin{tabular}{|c|c|c|c|c|c|c|c|}
\hline Sinus Diameter & No. of Pts. & $\begin{array}{c}\text { Mean Medionecrosis } \\
\text { Score }\end{array}$ & $\begin{array}{l}\text { Mean Fibrosis } \\
\text { Score }\end{array}$ & $\begin{array}{l}\text { Mean CMD } \\
\text { Score }\end{array}$ & $\begin{array}{l}\text { Mean SMD } \\
\text { Score }\end{array}$ & $\begin{array}{c}\text { Mean Elastic } \\
\text { Fragmentation Score }\end{array}$ & $\begin{array}{c}\text { Mean Composite } \\
\text { Score }\end{array}$ \\
\hline$\leq 35 \mathrm{~mm}$ & $6(24 \%)$ & 0.0 & 0.33 & 0.16 & 0.16 & 0.83 & 1.5 \\
\hline $41-45 \mathrm{~mm}$ & $5(20 \%)$ & 0.2 & 0.2 & 0.8 & 1.2 & 1.4 & 3.8 \\
\hline $46-50 \mathrm{~mm}$ & $3(12 \%)$ & 0.0 & 0.33 & 1.33 & 1.33 & 2.0 & 4.33 \\
\hline$\geq 51 \mathrm{~mm}$ & $2(8 \%)$ & 0.0 & 0.0 & 3.3 & 2.0 & 3.0 & 8.0 \\
\hline Total & $25(100 \%)$ & 0.4 (mean) & 0.2 (mean) & 1.16 (mean) & 0.8 (mean) & 1.4 (mean) & 3.60 (mean) \\
\hline
\end{tabular}

$\mathrm{CMD}=$ Cystic Medial Degeneration; SMD $=$ Smooth Muscle Disarray .

Table 2. Histopatholocical grading at site 2-Mid ascending aorta.

\begin{tabular}{|c|c|c|c|c|c|c|c|}
\hline $\begin{array}{l}\text { Mid Asc. Ao. } \\
\text { Diameter }\end{array}$ & No. of Pts. & $\begin{array}{c}\text { Mean Medionecrosis } \\
\text { Score }\end{array}$ & $\begin{array}{c}\text { Mean Fibrosis } \\
\text { Score }\end{array}$ & $\begin{array}{c}\text { Mean CMD } \\
\text { Score }\end{array}$ & $\begin{array}{c}\text { Mean SMD } \\
\text { Score }\end{array}$ & $\begin{array}{c}\text { Mean Elastic } \\
\text { Fragmentation Score }\end{array}$ & $\begin{array}{c}\text { Mean } \\
\text { Composite Score }\end{array}$ \\
\hline$\leq 35 \mathrm{~mm}$ & $10(40 \%)$ & 0.0 & 0.20 & 0.30 & 0.20 & 0.60 & 1.3 \\
\hline $41-45 \mathrm{~mm}$ & $4(16 \%)$ & 0.0 & 0.0 & 0.75 & 0.5 & 1.0 & 2.25 \\
\hline $46-50 \mathrm{~mm}$ & $3(12 \%)$ & 0.0 & 0.33 & 1.0 & 0.67 & 0.67 & 2.66 \\
\hline$\geq 51 \mathrm{~mm}$ & $4(16 \%)$ & 0.0 & 0.0 & 0.5 & 0.5 & 0.75 & 1.75 \\
\hline Total & $25(100 \%)$ & 0.0 (mean) & 0.12 (mean) & 0.52 (mean) & 0.32 (mean) & 0.72 (mean) & 1.68 (mean) \\
\hline
\end{tabular}

$\mathrm{CMD}=$ Cystic Medial Degeneration; $\mathrm{SMD}=$ Smooth Muscle Disarray. 


\subsection{Findings at Distal Ascending Aorta Level (Table 3)}

For aortic diameters: $\leq 35 \mathrm{~mm}, 36-40 \mathrm{~mm}, 41-45 \mathrm{~mm}$, $46-50 \mathrm{~mm}$ and $\geq 51 \mathrm{~mm}$, the mean composite HPE T Score was $0.38,0.87,1.25,0.0$ and 0.0 respectively. The HPE T Score was not in relation to aortic diameter having $R$ value $=0.191$ and $p$ value $=0.180$.

\subsection{Other Observations}

In further analysis, pearson correlation was applied to each histopathological findings used to grade the changes in this study. It was found that among 5 types of histopathological character studied, only smooth muscle cell disarray with $R$ value $=0.540(p$ value 0.005$)$ and elastic fragmentation with $\mathrm{R}$ value $=0.592$ ( $\mathrm{p}$ value 0.002 ) have significant correlation. Thus it can be postulated that elastic fragmentation and smooth muscle cell disarray are the two significant determinants causing aortic dilatation or dissection in ascending aorta of patients with BAV.

\section{Discussion}

Degenerative changes have been noticed in ascending aorta of Bicuspid Aortic Valve (BAV), though clinical significance has not yet established but signifies a poor outcome in terms of future complications. Aortic dilatetion is frequently associated with Bicuspid (BAV), irespective of haemodynamic status of aortic valve.

Borger A. Michael, David E. Tirone et al., in a study concluded that patients undergoing operations for bicuspid aortic valve disease should be considered for concomitant replacement of the ascending aorta if the diameter is $4.5 \mathrm{~cm}$ or greater [7].

According to AHA guidelines 2006, for management of valvular heart disease there is recommendation to replace ascending aorta if $>4.5 \mathrm{~cm}$ in diameter in patients of BAV undergoing aortic valve replacement or $>5 \mathrm{~cm}$ in isolation [8]. However the literature is silent on the extent of resection of ascending aorta in BAV patients. In general, resection only involves the sinuses and proximal ascending aorta, leaving the distal aortic segment in situ which may predispose the patient to future dissections and aneurysm formation. So whether the degenerative changes are limited to the aortic sinuses and proximal ascending aorta or even to the distal ascending aorta is still a matter of anticipation. Therefore some further studies are needed to acknowledge the extent of degenerative process in ascending aorta of BAV patients. Thus the purpose of our study was to find out the extent of aortic involvement in the degenerative process in patients with BAV.

In our study, we found that, if total of all HPE Score of 25 patients is compared at three levels of ascending aorta, degenerative changes were mostly manifested at the level of aortic sinuses. There is a linear relation between aortic diameter and histopathological scores [HPE T Score $=$ $-5.139+(0.188 \times$ Ao Sinus Diameter in $\mathrm{mm})]$ at sinus level. Not only the degenerative changes, but the aortic dilatation was also found to be maximum at sinus level. At other sites of ascending aorta, the degenerative changes were found only where dilatation was present, though they were not in statistically significant relationship. Literature already proven that tricuspid aortic valve patients did not show further aortic dilation after valve replacement but only valve replacement could not prevent progressive aortic dilation in BAV [9]. All these data derived observations show that: at time of dealing diseased BAV, if aortic sinuses and ascending aorta is dilated, than the dilated part needs to be replaced. In case of non-dilated aortic root, one should opt to replace the sinus part for prevention of future consequences by aortic degeneration.

Observation favors the presence of cystic medial degeneration, smooth muscle disarray and elastic fragmentation as predominant degenerative changes leading to aortic dilatation.

In summary, the mid and distal ascending aorta found to be less affected with degenerative changes in BAV patients. Aortic sinus is the most affected part of ascending aorta and degenerative changes may be found without any obvious dilatation $(<4.5 \mathrm{~cm})$.

Table 3. Histopatholocical grading at site 3-distal ascending aorta.

\begin{tabular}{|c|c|c|c|c|c|c|c|}
\hline $\begin{array}{l}\text { Distal Asc. Ao. } \\
\text { Diameter }\end{array}$ & No. of Pts. & $\begin{array}{l}\text { Mean Medionecrosis } \\
\text { Score }\end{array}$ & $\begin{array}{l}\text { Mean Fibrosis } \\
\text { Score }\end{array}$ & $\begin{array}{l}\text { Mean CMD } \\
\text { Score }\end{array}$ & $\begin{array}{l}\text { Mean SMD } \\
\text { Score }\end{array}$ & $\begin{array}{c}\text { Mean Elastic } \\
\text { Fragmentation Score }\end{array}$ & $\begin{array}{c}\text { Mean Composite } \\
\text { Score }\end{array}$ \\
\hline$\leq 35 \mathrm{~mm}$ & $13(52 \%)$ & 0.23 & 0.0 & 0.07 & 0.07 & 0.15 & 0.38 \\
\hline $36-40 \mathrm{~mm}$ & $8(32 \%)$ & 0.0 & 0.0 & 0.12 & 0.37 & 0.37 & 0.87 \\
\hline $41-45 \mathrm{~mm}$ & $3(12 \%)$ & 0.0 & 0.0 & 1.0 & 0.33 & 0.33 & 1.25 \\
\hline $46-50 \mathrm{~mm}$ & $1(4 \%)$ & 0.0 & 0.0 & 0.0 & 0.0 & 0.0 & 0.0 \\
\hline$\geq 51 \mathrm{~mm}$ & $0(0.0 \%)$ & 0.0 & 0.0 & 0.0 & 0.0 & 0.0 & 0.0 \\
\hline Total & $25(100 \%)$ & 0.12 (mean) & 0.0 (mean) & 0.20 (mean) & 0.20 (mean) & 0.28 (mean) & 0.68 (mean) \\
\hline
\end{tabular}

$\mathrm{CMD}=$ Cystic Medial Degeneration; $\mathrm{SMD}=$ Smooth Muscle Disarray. 


\section{Conclusion}

In patients of Bicuspid Aortic Valve, there is a definite relationship between the histopathological degeneration of aortic media and aortic diameter but limited up to the sinus level only. Though, some degree of insignificant degenerative changes also noticed at mid ascending and distal ascending aortic levels. Therefore it can be postulated that aortic root (replacement or aortoplasty) can be performed during aortic valve replacement or repair surgeries, even without significant dilatation $(<4.5 \mathrm{~cm})$ to prevent future complications of aneurysm or dissection. In case, if the dilatation of ascending aorta extends beyond aortic root then the excision must extend up to the dilated portion.

\section{Limitations}

This is a pilot study requiring surgical intervention for aortic biopsy hence normal candidates of bicuspid aortic valve were not involved for control group. Sample size need to be large for making some of observations statistically significant.

\section{REFERENCES}

[1] C. Ward, "Clinical Significance of the Bicuspid Aortic Valve," Heart, Vol. 83, No. 1, 2000, pp. 81-85. doi:10.1136/heart.83.1.81

[2] V. A. McKusick, "Association of Congenital Bicuspid Aortic Valve and Erdheim's Cystic Medial Necrosis," Lancet, Vol. 299, No. 7758, 1972, pp. 1026-1027. doi:10.1016/S0140-6736(72)91211-1

[3] M. G. Keane, S. E. Wiegers, T. Plappert, et al., "Bicuspid
Aortic Valves Are Associated with Aortic Dilatation out of Proportion to Coexistent Valvular Lesions," Circulation, Vol. 102, No. 19, 2000, pp. III35-III39. doi:10.1161/01.CIR.102.suppl_3.III-35

[4] D. E. Tirone and B. A. Michael, "Management of the Valve and Ascending Aorta in Adults with Bicuspid Aortic Valve," Disease Thoracic \& Cardiovascular Surgery, Vol. 17, No. 2, 2005, pp. 143-147.

[5] T. J. Schlatmann and A. E. Becker, "Histologic Changes in the Normal Aging Aorta: Implications for Dissecting Aortic Aneurysm," American Journal of Cardiology, Vol. 39, No. 1, 1977, pp. 13-20. doi:10.1016/S0002-9149(77)80004-0

[6] M. de Sa, Y. Moshkovitz, J. Butany and T. E. David, "Histologic Abnormalities of the Ascending Aorta and Pulmonary Trunk in Patients with Bicuspid Aortic Valve Disease: Clinical Relevance to the Ross Procedure," The Journal of Thoracic and Cardiovascular Surgery, Vol. 118, No. 4, 1999, pp. 588-594. doi:10.1016/S0022-5223(99)70002-4

[7] M. A. Borger, M. Preston, T. E. David, et al., "Should the Ascending Aorta Be Replaced More Frequently in Patients with Bicuspid Aortic Valve Disease," The Journal of Thoracic and Cardiovascular Surgery, Vol. 128, No. 5, 2004, pp. 677-683.

[8] O. R. Bonow, "2008 Focused Update Incorporated into the ACC/AHA 2006 Guidelines for the Management of Patients with Valvular Heart Disease," Circulation, Vol. 118, No. 15, 2008, pp. e523-e661.

[9] M. D. Yasuda-Hisayo, et al., "Failure to Prevent Progressive Dilation of Ascending Aorta by Aortic Valve Replacement in Patients with Bicuspid Aortic Valve: Comparison with Tricuspid Aortic Valve," Circulation, Vol. 108, No. 1, 2003, pp. 291-294. 


\section{Annexure 1}

\section{Histological Grading System Details:}

Fibrosis: Defined as an increase in interstitial collagen. Sections will be examined at a magnification of 100 times. Four grades will be recognized: grade 0 normal, grade 1, an increase in collagen content in an area comprising less than one third of the total width of the media or focal accumulation of collagen spread through the section; grade 2, an increase in collagen in an area consisting of between one third and two thirds of the total width of the media or multiple small areas that together could represent the same; grade 3, an increase of collagen in an area comprising more than two thirds of the total width of the media. These areas of medial damage are large, and collagen is increased significantly.

Medionecrosis: Defined as a focal loss of smooth muscle cell nuclei in the media. It has been graded at a magnification of 100 times. Four grades will be recognized: grade 0 normal, grade 1 , focal loss of nuclei in an area consisting less than one third of the total width of the media; grade 2, focal loss of nuclei in an area consisting of one and two thirds of the medial thickness; grade 3 , focal loss of nuclei in an area comprising more than two thirds of the total media thickness or batched areas that together could represent the same.

Accumulation of mucoid material (Cystic Medial Degeneration = CMD): The mucoid material or mucopolysaccharides will be observed in the presence of intact elastic lamellae and in the presence of fragmented elastic fibers; Four grades of accumulation of mucoid material will be defined at a magnification of 100 times: grade 0 no accumulation of mucoid material i.e. mucoid cysts, grade 1, minute foci of mucoid material (cysts) present within a single lamellar unit, not encompassing its entire width; grade 2, size or number of cysts increased, and the mucoid material covered the total width of 1 lamellar unit or equivalent areas (width) in different regions of the media; grade 3 , the cysts will be large and extended in area over more than 1 lamellar unit, either because of focal aggregation of small cysts with intact elastic lamellae or because of large cysts in an area with fragmented elastic fibers forming pools of mucoid material.

Changes in the smooth muscle cells orientation (SMD = Smooth Muscle Disarray): Because changes in smooth muscle cell orientation are not always associated with severe elastic fragmentation, this feature has been classified separately. These changes refer to different orientation of the cells so that the longitudinal aspect is not seen; instead, a transverse view of the cells is observed. Three grades were recognized at magnification of 100 times: grade 0 normal orientation, grade 1 , small foci with change in the orientation of the smooth muscle cells, which could be spread in different areas; grade 2, area with change in the smooth muscle cell orientation or several areas that together represent between one third and one half of the thickness of the media; grade 3, large area of changes in the smooth muscle cell orientation, associated with severe elastic fragmentation and consisting more than one half of the media thickness, giving a very disorganized appearance to the specimen.

Elastic fragmentation: Defined as focal fragmentation of elastic lamellae in the media of the aorta. Grading done as described in above paragraph.

HPE Scores were obtained by adding individual grading scores.

All data recorded on predesigned proforma and managed on excel spread sheet. 